\title{
PENGEMBANGAN MODEL PEMBELAJARAN MOTORIK UNTUK ANAK SEKOLAH DASAR
}

\author{
Jumesam $^{1}$, Nopi Hariadi ${ }^{2}$ \\ Email: mr.jumesam.lombok@gmail.com ${ }^{1}$, nopihariadi@ hamzanwadi.ac.id ${ }^{2}$ \\ 1,2 Program Studi Penjaskesrek, Fakultas Ilmu Pendidikan, Universitas Hamzanwadi
}

\begin{abstract}
Abstrak
Penelitian ini bertujuan untuk (1) Mengembangkan model pembelajaran motorik Penjasorkes, (2) Mengetahui hasil pembelajaran motorik, dan (3) Mengetahui respon peserta didik terhadap pembelajaran motorik dengan menggunakan pendekatan bermain. Penelitian ini merupakan Research and Development ( $R$ \& D). Model pengembangan meliputi (1) Tahap studi pendahuluan, (2) Tahap penyusunan draft produk dan (3) Tahap pengembangan dan evaluasi. Tahap pengembangan dan evaluasi berupa uji validitas pakar, uji coba terbatas dan uji coba luas. Subjek uji coba penelitian dan pengembangan ini adalah 1 pakar pembelajaran, 1 guru Penjasorkes dan 48 peserta didik (dari 2 kelas) yaitu kelas I, dan II untuk uji coba terbatas serta 1 guru Penjasorkes dan 76 peserta didik (dari 3 kelas) yaitu kelas I, II dan III untuk uji coba luas. Observasi, wawancara dan angket digunakan untuk mengumpulkan data pada langkah uji coba. Analisis data menggunakan statistik deskriptif untuk mengevaluasi model pembelajaran motorik dengan pendekatan bermain. Pre-test dan post-test diberikan pada uji coba luas untuk mengetahui kemampuan sebelum dan sesudah dilakukan pembelajaran. Hasil yang diperoleh pada penelitian ini adalah langkah-langkah pembelajaran dengan pendekatan bermain terdiri atas motivation, ask, hypothesis, investigate, create, discuss dan reflect. Skor validasi dari uji pakar adalah 4,3 dari nilai maksimum 5, yang berarti bahwa model ini masuk dalam kategori bagus. Hasil pre-test dan post-test menunjukkan adanya peningkatan nilai sebesar 45,4 yaitu dari 25,3 menjadi 70,7. Respon peserta didik mengenai pembelajaran motorik dengan pendekatan bermain ini menunjukkan bahwa motivasi belajar Penjasorkes, kebebasan mengeluarkan pendapat, peran aktif peserta didik, kerjasama serta kemampuan menyelidiki dan memahami materi adalah tinggi/positif.
\end{abstract}

Kata Kunci: Model Pengembangan, Pembelajaran Motorik.

\section{Abstract}

This study aims to (1) develop the motor learning model of Physical Education, (2) Know the results of motor learning, and (3) Know the responses of students to motor learning to use the play approach. This research is a Research and Development $(R \& D)$. A development model includes (1) The preliminary study stage, (2) The product draft preparation stage, and (3) The development and evaluation stage. A development and evaluation stages are as expert validity tests, limited trials, and extensive trials. A subject of this research and development trial was 1 learning expert, 1 Physical Education teacher, and 48 students (from 2 classes) namely class I, and II for limited trials and 1 Physical Education teacher and 76 students (from 3 classes) namely class I, II and III for broad trials. Observations, interviews, and questionnaires were used to collect data in the trial step. A data analysis used descriptive statistics to evaluation given the motor learning model with a playful approach. Pre-test and post-test were given in a broad trial to determine the ability before and after learning. Result in this study is learning steps with a playful approach comprising motivation, ask 
hypothesis, investigate, create, discuss, and reflect. validation score of the expert test is 4.3 out of a maximum value of 5, so comprising this model is in a good category. A result of the pre-test and posttest showed an increase in the value of 45.4, from 25.3 to 70.7. A response of students regarding motor learning with this playing approach shows that the motivation to learn Physical Education, freedom of expression, the active role of students, cooperation, and the ability to investigate and understand the material is high/positive.

Keywords: Development Model, Motor Learning.

\section{A. Pendahuluan}

Menganalisis proses belajar mengajar pada intinya tertumpu pada suatu persoalan, yaitu bagaimana guru memberi kemungkinan bagi peserta didik agar terjadi proses belajar yang efektif atau dapat mencapai hasil sesuai dengan tujuan. Persoalan ini membawa implikasi sebagai berikut: (1) guru harus mempunyai pengetahuan tentang mengajar dan dasar-dasar teori belajar, (2) guru harus dapat mengembangkan sistem pengajaran, (3) guru harus mampu melakukan proses belajar mengajar yang efektif, (4) guru harus mampu melakukan penilaian hasil belajar sebagai dasar umpan balik bagi seluruh proses yang ditempuh. Terkait dengan hal itu, maka sangat dibutuhkan studi yang matang dan mendalam, mengenai model dan metode yang tepat untuk pembelajaran Penjasorkes khususnya pembelajaran pada komponen motorik. Dengan demikian melalui penelitian ini diharapkan akan didapat solusi atau jawaban tentang model dan metode pembelajaran yang tepat untuk mengajarkan pembelajaran motorik pada peserta didik Sekolah Dasar. Pendekatan bermain adalah model dan metode yang digunakan dalam penelitian ini, khususnya pembelajaran motorik. Bermain adalah sesuatu yang menyenangkan bagi peserta didik, dengan bermain peserta didik tidak merasakan lelah atau terbebani dalam melakukan aktivitas tetapi menjadi sesuatu yang menyenangkan, dengan kata lain tidak membosankan, maka akan terjadilah pembelajaran yang sesungguhnya.mDalam pembelajaran aspek motorik yang mengasyikkan adalah utamanya dicurahkan pada aspek kandungannya dari aktivitas bermain yang menyenangkan. Pembelajaran motorik dengan pendekatan bermain penanda bertujuan agar peserta didik dalam melakukan permainan terfokus pada model dan metode pembelajarannya, selain itu, agar peserta didik dalam melakukan gerakannya walaupun penuh kegembiraan dan keceriaan namun tujuan dari pembelajarannya tetap tercapai sesuai dengan yang diinginkan. Jamal Ma'mur Asmani (2009: 14) menyatakan munculnya fenomena ini, diharapkan mampu melahirkan kesadaran akan pentingnya belajar dari mulai usia dini sampai tua, bahkan sampai ajal datang. Inilah falsafah pendidikan yang terkenal dengan sebutan long life education. Tidak ada batas dalam belajar, selama napas masih di kandung badan, selama itu pula harus belajar. Disinilah peran orang tua sangat dibutuhkan, tidak peduli apakah peserta didik masuk sekolah atau tidak, tugas orangtua-lah untuk memahami peserta didik dengan baik sehingga tahu kapan harus memperkenalkan sebuah keterampilan, kapan harus menundanya, kapan harus memacunya lebih kencang, dan bagaimana membuat peserta didik menjadi tertarik untuk mempelajari sesuatu tanpa harus dipaksa oleh waktu dan penilaian pihak lain.

\section{B. Metode}

Jenis data yang diperoleh dalam penelitian dan pengembangan ini berupa data kualitatif dan data kuantitatif.

1. Instrumen Pengumpulan Data

Instrumen pengumpulan data pada penelitian ini digunakan untuk mengumpulkan data pada uji validitas dari pakar, uji coba terbatas dan uji coba luas. Uji validitas pakar menggunakan instrumen lembar validasi pakar pembelajaran. Uji coba terbatas dan uji 
coba luas menggunakan instrumen lembar observasi, pedoman wawancara, dan dokumentasi.

2. Teknik Analisis Data

Analisis terhadap data validasi dari pakar adalah dengan menggunakan teknik analisis deskriptif. Frekuensi tiap-tiap skor dihitung untuk mengetahui persentase dari kategori sangat tinggi (4), tinggi (3), rendah (2), sangat rendah (1). Data dari hasil observasi dan angket dianalisis teknik statistik deskriptif dengan mengelompokkan data tersebut ke dalam empat kategori. Kategori hasil pengukuran ini ditunjukkan pada tabel berikut (Djemari Mardapi, 2008: 123).

Tabel 1. Kategori Untuk Skor Peserta didik

\begin{tabular}{clc} 
No. & \multicolumn{1}{c}{ Skor Peserta didik } & Kategori \\
\hline 1 & $x \geq \bar{x}+1 S B_{x}$ & Sangat Tinggi \\
2 & $\bar{x}+1 S B_{x}>x \geq \bar{x}$ & Tinggi \\
3 & $\bar{x}>x \geq \bar{x}-1 S B_{x}$ & Rendah \\
4 & $x<\bar{x}-1 S B_{x}$ & Sangat Rendah \\
\hline
\end{tabular}

Keterangan:

$\bar{x} \quad=$ Rerata skor keseluruhan peserta didik

$\mathrm{SBx}=$ Simpangan baku skor keseluruhan peserta didik dalam satu kelas

$\mathrm{X}=$ Skor yang dicapai peserta didik

Penafsiran hasil tes untuk mengetahui tingkat penguasaan yang dicapai menggunakan kriteria menurut Djemari Mardapi (2008: 61) yaitu:

$$
\begin{array}{ll}
90 \%-100 \% & =\text { Sangat Tinggi } \\
80 \%-89 \% & =\text { Tinggi } \\
70 \%-79 \% & =\text { Rendah } \\
<70 \% & =\text { Sangat Rendah }
\end{array}
$$

3. Analisis Data Pre Test dan Post Test

Rata-rata nilai Pre test adalah 25,3. Kemudian setelah dilaksanakan pembelajaran dengan pendekatan bermain, rata-rata nilai Post test yang diperoleh peserta didik adalah 70,7. Berarti terjadi peningkatan (gain) sebesar 45,4.

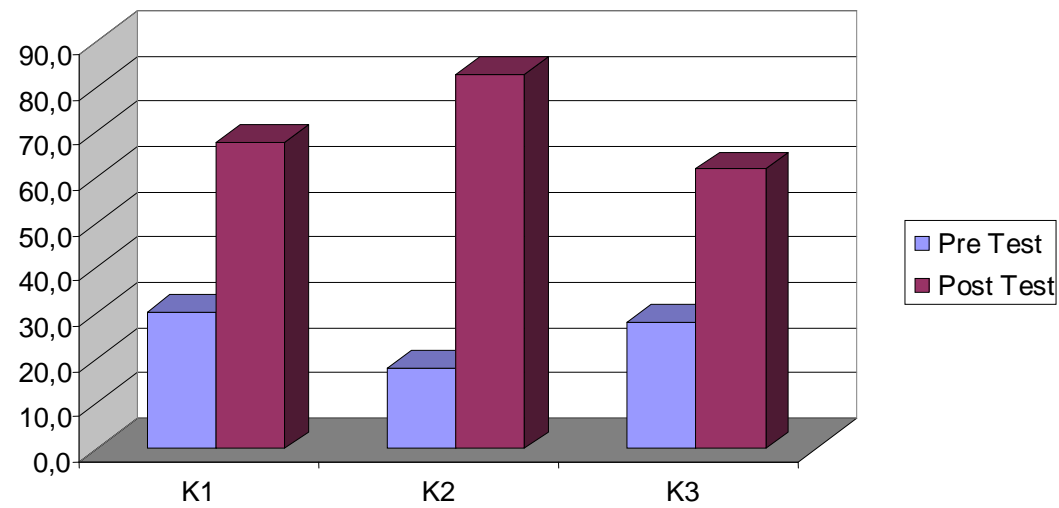

Diagram 1. Diagram Batang Nilai Rata-rata Pre Test dan Post Test Uji Coba Luas

Tabel 2. Gain Dari Nilai Pre Test dan Post Test 
Creating Productive and Upcoming Sport Education Profesional Hmzanwadi University

Vol.3, No.2, Desember 2020, Hal. 119-126

e-ISSN 2614-8781

\begin{tabular}{cccccc} 
Nama Sekolah & Kelas & $\begin{array}{c}\text { Jumlah Peserta } \\
\text { didik }\end{array}$ & Pre Test & $\begin{array}{c}\text { Nilai } \\
\text { Post } \\
\text { Test }\end{array}$ & Gain \\
\hline & I & 26 & 30,4 & 67,7 & 37,3 \\
SDN 07 Selebung & II & 22 & 17,7 & 82,7 & 65,0 \\
Ketangga & III & 28 & 27,9 & 61,8 & 33,9 \\
\cline { 2 - 6 } & & Rata-Rata & 25,3 & 70,7 & 45,4
\end{tabular}

\section{Hasil dan Pembahasan}

Hasil

1. Uji Coba Produk

Uji coba yang dilakukan bertujuan untuk menyempurnakan model pembelajaran dengan mempraktekkannya secara langsung di lapangan. Uji coba yang dilakukan didasarkan adaptasi dari Nana Syaodih Sukmadinata (2007: 184) yang meliputi tiga tahap yaitu:

a. Uji pakar atau ahli dilakukan oleh pakar pembelalajaran untuk menilai dan memberikan masukan terhadap draft produk awal. Uji pakar ini untuk memvalidasi produk sebelum dilakukan uji coba lapangan.

b. Uji coba terbatas ini dilakukan pada 2 kelas. Pada pelaksanaan uji coba ini, guru melaksanakan pembelajaran sesuai dengan model yang telah dibuat. Selama kegiatan pembelajaran berlangsung, peneliti melakukan pengamatan dan mencatat hal-hal penting selama proses pembelajaran baik aktivitas peserta didik maupun guru. Setelah kegiatan mengajar selesai dilakukan, peneliti mengadakan pertemuan dengan guru untuk mendiskusikan pembelajaran yang telah dilaksanakan peserta didik. Hal-hal yang didiskusikan meliputi kegiatan pembelajaran yang telah dilakukan sebagai penerapan dari model pembelajaran motorik yang dikembangkan. Guru dapat memberikan masukan untuk penyempurnaan model pembelajaran. Pada uji coba ini, wawancara, praktek, dan pengamatan dikumpulkan dan dianalisis yang kemudian digunakan untuk merevisi produk.

c. Uji coba luas diterapkan pada 3 kelas dari sekolah yang sama. Pada tahap ini dilakukan pembelajaran dan diobservasi. Kegiatan yang dilakukan hampir sama dengan kegiatan yang dilakukan pada uji coba terbatas. Perbedaannya adalah pada uji coba luas ini, subjek uji cobanya lebih banyak dan lebih luas. Data kuantitatif yaitu kemampuan sebelum dan sesudah menggunakan pembelajaran (pre test dan post test) dikumpulkan untuk dianalisis. Masukan-masukan dari tahap ini digunakan untuk penyempurnaan draft produk sehingga dihasilkan produk akhir berupa model pembelajaran motorik untuk peserta didik Sekolah Dasar, mata pelajaran Penjasorkes.

2. Subjek Coba

Subjek uji coba dalam penelitian dan pengembangan ini adalah sebagai berikut:

a. Uji pakar/ahli: 1 orang pakar pembelajaran yang berkompeten di dalam pembelajaran motorik.

b. Uji coba terbatas: 2 kelas yaitu kelas 1 ( 1 orang guru Penjasorkes dan 26 orang peserta didik), dan kelas 2 (1 orang guru Penjasorkes dan 22 orang peserta didik), SDN 07 Selebung Ketangga Kecamatan Keruak Kabupaten Lombok Timur Provinsi Nusa Tenggara Barat.

c. Uji coba luas: 3 kelas yaitu kelas 1 (1 orang guru Penjasorkes dan 26 orang peserta didik), kelas 2 ( 1 orang guru Penjasorkes dan 22 orang peserta didik), kelas 3 (1 orang guru Penjasorkes dan 28 orang peserta didik), SDN 07 Selebung Ketangga Kecamatan Keruak Kabupaten Lombok Timur Provinsi Nusa Tenggara Barat. 


\section{Kajian Produk Akhir}

Prodok akhir model pembelajaran Penjasorkes dengan pendekatan bermain dengan topik pembelajaran motorik hasil penelitian dan pengembangan ini adalah pembelajaran dengan pendekatan bermain penanda. Tipe ini dapat diterapkan untuk peserta didik kelas I, II, dan III Sekolah Dasar yaitu dengan mengajukan pertanyaan kepada peserta didik dan memberi kesempatan kepada peserta didik untuk merancang dan melakukan penyelidikan sendiri, kemudian memecahkan masalah yang diangkat. peserta didik masih membutuhkan bimbingan dari guru untuk mengungkapkan pendapat atau ide dengan kata-kata atau bahasa tulisan yang tepat. Langkah-langkah pembelajaran dengan pendekatan bermain ini terdiri dari 7 langkah yaitu: ask, hypothesis, investigate, create, discuss, dan reflect. Langkah-langkah ini sejalan dengan metode ilmiah yaitu identifikasi masalah, mengajukan hipotesis, pengujian hipotesis, dan kesimpulan. Hal lain yang mempengaruhi pembelajaran motorik dengan pendekatan bermain ini adalah lingkungan belajar yang memberi dukungan dan kesempatan kepada peserta didik untuk melakukan penyelidikan di dalam belajar Penjasorkes. Keceriaan, tantangan, kesempatan bekerjasama juga memberi lingkungan belajar yang baik bagi peserta didik.

Pembahasan

1. Spesifikasi Produk yang Dikembangkan

Produk yang dikembangkan dalam penelitian ini memiliki spesifikasi sebagai berikut:

a. Produk yang dikembangkan adalah model pembelajaran motorik dengan pendekatan bermain penanda yang dituangkan dalam bentuk buku. Buku ini berisi penjelasan mengenai pembelajaran motorik yang menarik dan bermanfaat dalam menunjang proses pertumbuhan dan perkembangan peserta didik, sedangkan RPP (Rencana Pelaksanaan Pembelajaran) memuat langkah-langkah pembelajaran dengan model dan metode pembelajaran motorik sesuai dengan Kurikulum 2006 (KTSP).

b. Scope model pembelajaran ini adalah digunakan untuk mata pelajaran Penjasorkes untuk peserta didik Sekolah Dasar kelas bawah.

c. Kompetensi yang hendak dicapai dengan model pembelajaran ini adalah peserta didik dapat merancang dan melakukan penyelidikan sederhana terhadap topik yang di bahas.

d. Pendekatan pembelajaran yang digunakan dalam pembelajaran ini adalah bermain penanda, pembelajaran motorik yang menarik dan bermanfaat yang di dalamnya terdapat metode praktik dan diskusi.

e. Evaluasi yang dilakukan dalam pembelajaran motorik ini dengan memberikan tes yang berisi pemahaman peserta didik mengenai konsep bermain yang sederhana, menarik dan menyenangkan serta bermanfaat bagi pertumbuhan dan perkembangannya.

2. Asumsi dan Keterbatasan Pengembangan

Asumsi dalam penelitian dan pengembangan model pembelajaran motorik ini adalah penelitian dan pengembangan ini dilakukan pada peserta didik Sekolah Dasar. Dengan asumsi bahwa peserta didik Sekolah Dasar berada dalam proses pertumbuhan dan perkembangan yang cepat sehingga memerlukan perlakuan motorik yang tepat dalam menunjang dan mendukung kelancaran proses pertumbuhan dan perkembangannya. Model pembelajaran motorik dikembangkan dalam penelitian ini dibuat untuk satu topik yaitu untuk peserta didik Sekolah Dasar kelas bawah dengan pendekatan bermain penanda. Hal ini dilakukan karena adanya keterbatasan waktu dan dana. Selain itu pada saat uji coba model pembelajaran di Sekolah Dasar membutuhkan waktu untuk persiapan dan pelaksanaan sendiri.

3. Model Pengembangan 
Nana Syaodih Sukmadinata (2010: 164) menyatakan penelitian pengembangan atau yang sering disebut dengan istilah Research and Development ( $\mathrm{R} \& \mathrm{D})$ adalah suatu proses atau langkah-langkah untuk mengembangkan suatu produk baru atau menyempurnakan produk yang telah ada, yang dapat dipertanggungjawabkan. Sedangkan model pembelajaran motorik yang dikembangkan dalam penelitian dan pengembangan di sini mengacu pada proses pembelajaran yang meliputi bertanya, menyelidiki solusi pemecahan, menghasilkan pengetahuan baru, mendiskusikan hasil penemuan dan pengalaman, dan merefleksikan penemuan baru yang ditemukan.

4. Prosedur Pengembangan

Prosedur pengembangan dalam penelitian ini diadaptasi dari model pengembangan menurut Borg \& Gall (1983: 775) dan juga Sugiyono (2010: 316) prosedur yang diadaptasi tersebut meliputi tiga tahap yaitu (1) tahap studi pendahuluan, (2) tahap penyusunan draft produk dan (3) tahap pengembangan dan evaluasi.

\section{Tahap Study Pendahuluan}

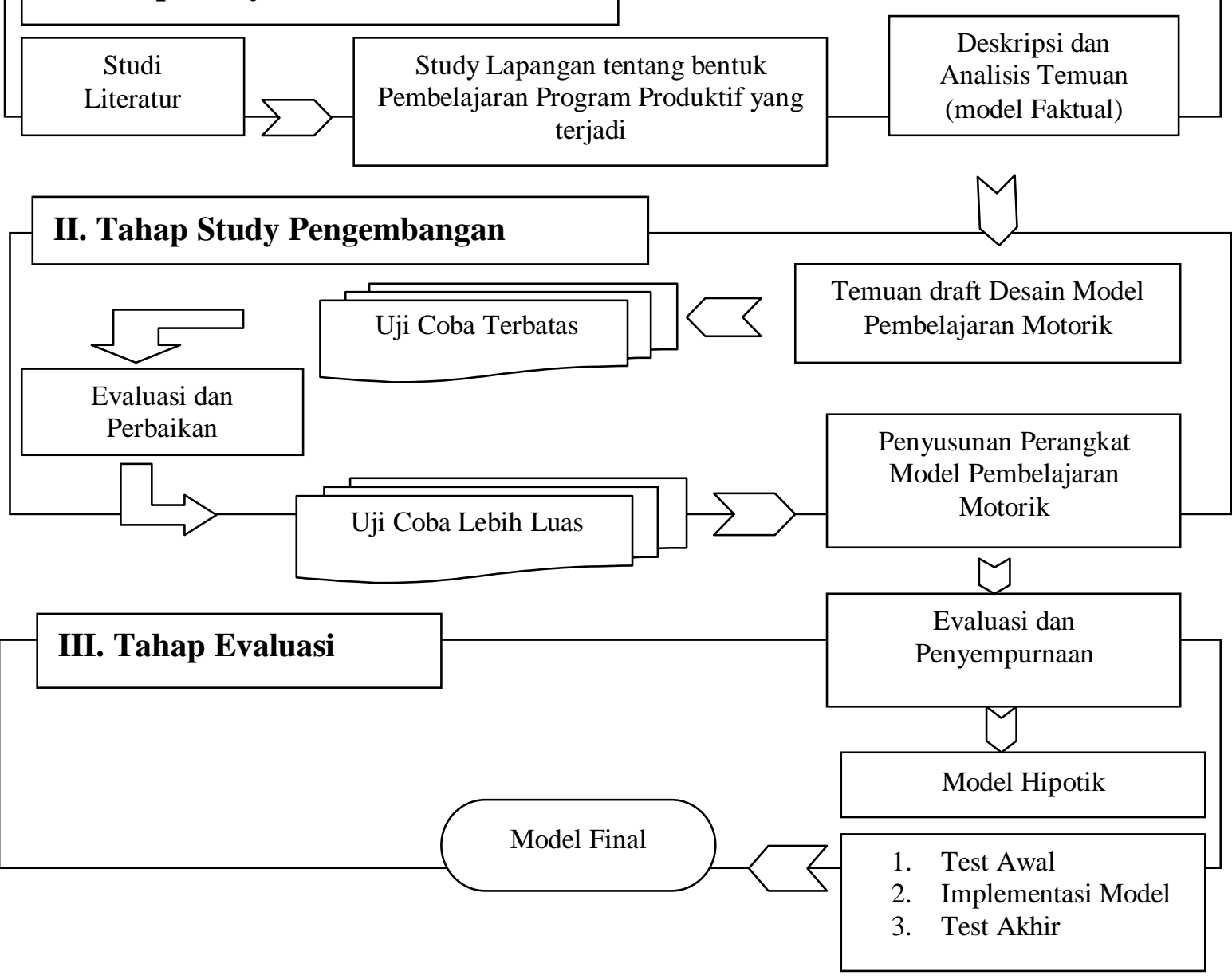

Gambar 2. Tahap Pengembangan Pembelajaran

I. Tahap Studi Pendahuluan

Tahap ini merupakan tahap pertama atau persiapan untuk pengembangan. Tahap ini terdiri dari studi kepustakaan dan survey lapangan. Hal-hal yang perlu dilihat adalah standar kompetensi, kompetensi dasar maupun materi pelajaran. Selain itu juga dilakukan kajian terhadap hasil-hasil penelitian yang berkenan dengan pembelajaran motorik. Survei lapangan dilaksanakan untuk mengetahui perencanaan dan pelaksanaan pembalajaran 
Penjasorkes di Sekolah Dasar. Survei ini dilakukan dengan wawancara, studi dokumenter dan observasi lapangan yaitu pengamatan pada waktu guru mengajar. Observasi di lapangan ini bertujuan untuk mengetahui proses pembelajaran yang dilakukan oleh guru maupun untuk melihat karakteristik dari peserta didik dalam mengikuti proses pembelajaran.

II. Tahap Penyusunan Draft Produk

Pada tahap ini langkah-langkah pembelajaran motorik dirancang dengan didasarkan pada analisis kebutuhan di atas. Kegiatan pembelajaran ini disusun dengan memperhatikan faktor keaktifan peserta didik dalam menyelidiki dan menemukan pengetahuan baru. Hasilnya adalah draft produk awal berupa model pembelajaran motorik Penjasorkes untuk peserta didik Sekolah Dasar. Draft produk awal ini berupa Buku Model Pembelajaran Penjasorkes yang memuat petunjuk pembelajaran motorik, Rencana Pelaksanaan Pembelajaran (RPP).

III. Tahap Pengembangan dan Evaluasi

Draft produk yang telah dihasilkan kemudian di uji coba untuk pengembangan lebih lanjut. Uji coba yang dilakukan berdasarkan adaptasi dari Nana Syaodih Sukmadinata (2007: 184) yang meliputi tiga tahap yaitu uji pakar, uji coba terbatas, dan uji coba luas. Uji pakar dilakukan untuk menguji kelayakan produk berupa model pembelajaran motorik sebelum diujicoba di lapangan. Pada tahap uji coba terbatas dan uji coba luas dilakukan pembelajaran motorik dan dilakukan pengamatan. Hasil ini kemudian sebagai dasar evaluasi untuk memperbaiki produk sehingga dihasilkan produk akhir.

\section{Simpulan}

Berdasarkan hasil penelitian dan pengembangan ini dapat ditarik kesimpulan yaitu 1). Langkah-langkah pembelajaran motorik dengan menggunakan pendekatan bermain untuk anak Sekolah Dasar adalah Motivation (memotivasi dengan kegiatan yang menarik), Ask (mengajukan pertanyaan), Hypothesis (mengajukan dugaan), Investigate (melakukan penyelidikan), create (menciptakan pengetahuan), Discuss (mendiskusikan hasil penyelidikan), dan Reflect (merefleksikan kegiatan yang telah dilakukan). Skor validasi dari pakar pembelajaran untuk model pembelajaran motorik dengan pendekatan bermain ini secara keseluruhan adalah 4,3 dari skor maksimum 5. Ini berarti model pembelajaran ini termasuk dalam kategori bagus, dan 2). Respon siswa terhadap pembelajaran motorik dengan pendekatan bermain tentang motivasi belajar Penjasorkes adalah tinggi (nilai 3,57), kebebasan mengeluarkan pendapat adalah tinggi (nilai 3,26), peran aktif siswa adalah tinggi (nilai 3,64), kerjasama dengan teman adalah tinggi (nilai 3,57), dan kemampuan menyelidiki dan memahami materi adalah tinggi (nilai 3,57), dan kemampuan motorik adalah tinggi $(3,57)$ dari skor maksimum 4.

\section{Daftar Pustaka}

Depdiknas. (2009). Himpunan peraturan perundang-undangan. Undang-undang sisdiknas tentang sistem pendidikan nasional. Bandung: Fokusmedia.

Djemari Mardapi. (2008). Teknik penyusunan instrumen tes dan nontes. Jogjakarta: Mitra Cendekia Press.

Hergenhahn B. R. \& Olson M. H. (2008). Theories of learning/teori belajar. Terjemahan oleh. Tri Wibowo, B.S. Edisi ketujuh. Jakarta: PT. Kencana Prenada Media Group.

Isnaini, L. M. Y. (2019). Aplikasi Latihan Mental Dalam Pembelajaran Gerak Untuk Meningkatkan KeterampilanPada Pembelajaran Pendidikan JasmaniOlahraga dan Kesehatan. Jurnal Porkes, 2(1), 17-25.

Muhammad Muhyi Faruq. (2009). Meningkatkan kecerdasan kinestetik melalui 70 permainan dengan cone. Jakarta: PT. Gramedia Widiasarana Indonesia. 
Nana Sudjana. (2009). Dasar-dasar proses belajar mengajar. Bandung: Sinar Baru Algensindo.

Nana Syaodih Sukmadinata. (2010). Metode penelitian pendidikan. Bandung: PT. Remaja Rosdakarya.

Prayoga, A. S., Utomo, A. W. B., \& Wahyudi, A. N. (2020). Upaya Meningkatkan Kompetensi Ketrampilan Gerak Dasar Lokomotor Lari Melalui Permainan Sederhana Di Kelas Iv Sekolah Dasar Negeri 02 Lego Kulon Kecamatan Kasreman Kabupaten Ngawi Tahun Ajaran 2019/2020. Jurnal Porkes, 2(2), 77-84.

Rusli Luthan. (2008). Belajar keterampilan motorik: pengantar teori dan metode. Jakarta: Depdiknas.

Sugiyono. (2010). Metode penelitian kuantitatif kualitatif dan $R \& D$. Bandung: Alfabeta.

Sukintaka. (2004). Teori pendidikan jasmani: Filosofi pembelajaran dan masa depan. Bandung: Nuansa Cendekia.

Wina Sanjaya. (2010). Strategi pembelajaran berorientasi standar proses pendidikan. Jakarta: PT. Kencana Prenada Media Group. 